Sitientibus Série Ciências Físicas 06: 17-22 (2010)

\title{
Longslit spectroscopy of the starburst galaxy HRG 02401
}

Espectroscopia de Fenda Longa da galáxia starburst HRG 02401

\author{
Vera A.F. Martin|* e Paulo C.R. Poppe \\ Departamento de Física / Observatório Astronômico Antares - UEFS \\ Av. Transnordestina, $\mathrm{s} / \mathrm{n}, \mathrm{km}$ 03, \\ BR 116, Campus da UEFS \\ Feira de Santana - BA - 44036-900
}
Max Faúndez-Abans, Mariângela de Oliveira-Abans, e Iranderly F. de Fernandes Laboratório Nacional de Astrofísica - MCT
R. Estados Unidos, 154, Bairro das Nações
Itajubá - MG - 37504-364

We investigate in detail the kinematics and morphology of the starburst galaxy HRG 02401. Our observational data were obtained at the 1.6-m OPD/LNA-MCT telescope with longslit spectroscopy. The original image has been enhanced to highlight some substructures and it has shown that HRG 02401 is in phase of active merging with a companion galaxy. The resulting tidal perturbations may have induced the apparent two-armed spiral pattern and driven a substantial fraction of disc gas inwards. We have been able to study the detailed picture of ionized gas motions up to galactocentric distances of $11 \mathrm{kpc}$ and to construct the stellar velocity field for the inner region. Although the optical ring is quite narrow, $\mathrm{H} \alpha$ emission is observed all the way through the center of the galaxy, indicating the presence of an extended gaseous disk. We have estimated nuclear redshift of $z=0.017$, corresponding to a heliocentric velocity of $5,206 \pm 13.01 \mathrm{~km} \mathrm{~s}^{-1}$. The errors in the fluxes were mostly caused by uncertainties in the placement of the continuum level. Some other physical parameters have been derived whenever possible. All spectra were reduced and analyzed in a homogeneous way with the standard IRAF procedures.

Key-words: Longslit Spectroscopy, Starburst Galaxy, Nuclear Redshift, Spectral Analysis.

Investigamos em detalhe a cinemática e a morfologia da galáxia "starburst" HRG 02401. Nossos dados experimentais foram obtidos através da espectroscopia de fenda longa no telescópio de 1,6-m OPD/LNA-MCT. A imagem original foi realçada para destacar algumas subestruturas e mostramos que a HRG 02401 está em interação com a galáxia companheira. As perturbações de maré resultantes podem ter induzido o padrão espiral de dois-braços aparentes, uma fração substancial do disco de gás apontando no interior. Temos sido capazes de estudar a imagem detalhada dos movimentos do gás ionizado até distâncias galactocêntricas de 11 kpc e de construir o campo de velocidade estelar para a região interior. Embora o anel óptico seja muito próximo, observamos a emissão de $\mathrm{H} \alpha$ ao longo da direção que atravessa o centro da galáxia, indicando a presença de um extenso disco gasoso. Temos estimado o "redshift" nuclear em $z=0.017$, correspondendo a uma velocidade heliocêntrica de $5,206 \pm 13.01 \mathrm{~km}$ ${ }^{-1}$. Os erros nos fluxos são em sua maioria causados por incertezas na localização do nível contínuo. Alguns outros parâmetros foram obtidos sempre que possível. Todos os espectros foram reduzidos e analisados de uma forma homogênea com os procedimentos padrões do IRAF.

Palavras-chaves: Espectroscopia de Fenda Longa, Galáxia 'Starburst', Deslocamento Nuclear para o Vermelho, Análises de Espectro.

*Endereço Eletrônico: vmartin@uefs.br 


\section{INTRODUCTION}

Galaxies with unusually high levels of star formation are referred to as starburst galaxies. They were first identified by their strong optical emission lines. The term "starburst" was originally coined by Weedman et al. [1] to indicate qualitatively that a galaxy is undergoing a period of intense star formation. It still lacks a precise definition and provides a blanket covering for all regions that have an above normal star formation rate. On the other hand, for the interacting galaxies it includes star formation enhanced by any process ranging from a mild perturbation to a collision.

In this work we present the first optical longslit spectroscopy for the galaxy HRG 02401, a SB (according to the NASA/IPAC Extragalactic Database) type peculiar galaxy seen face-on with an asymmetrical elliptical structure. The aim of the current study is to describe the main physical properties of this object. The spectra obtained with the $1.6-\mathrm{m}$ telescope of the Observatório do Pico dos Dias (OPD)-MCT/LNA-Brazil, shows a variety of interesting features and we have used diagnostic diagrams to classify this object as a Starburst galaxy, at a redshift of $5206.24 \pm 13.01$, corresponding to a distance of $71.32 \mathrm{Mpc}(\mathrm{H} 0=$ $73 \mathrm{~km} \mathrm{~s}^{-1} \mathrm{Mpc}^{(-1)}$.

\section{OBSERVATION AND DATA REDUCTION}

The optical spectrum was obtained using the Boller and Chivens spectrograph attached on the 1.6-m OPD Telescope on 2006 June, 28, with a $1200-\mathrm{s}$ integration. The configuration was a $3.0-$ arcsec-wide longslit centered on the optical peak and oriented at position angle 680 , shown schematically in Figure 1. The detector used was CCD WI-105 with $2048 \times 2048$ pixels, and a 600 lines $\mathrm{mm}^{-1}$ grating, blazed at $5850 \AA$,

\section{DISCUSSION AND CONCLUSION}

The $\mathrm{H} \alpha$ flux and equivalent width, in Fig- which provides a dispersion of $88.75 \AA \mathrm{mm}^{-1}$.

The scale of the frames on the spatial direction was 0.56 arcsec pixel ${ }^{-1}$, although the PSF of the standard star showed that the seeing was about 1.5 arcsec. The spectral resolution was matched to the $1.2 \AA$ pixel $^{-1}$, yielding an effective resolution of about $3.74 \AA$ (FWHM) and covering the $4623-7077 \AA$. The Table I gives some information about the HRG 02401 galaxy.

\section{SPATIAL MAPPING}

In order to make the most use of the spatial information that a longslit affords, the central $50.4^{\prime \prime}$ was divided into a series of $1.12^{\prime \prime}$ (390.9-pc) apertures. For each of resulting spectra, measurements were made of the total integrated flux of the spectrum, the slope of the continuum, the $\mathrm{H} \alpha$ line flux and equivalent width (EWHa), and where possible the $\mathrm{H} \beta$ line flux (see Figure 2).

\section{SPECTRAL ANALYSIS}

This galaxy includes some of the most important emission lines for ionization diagnostics: $\mathrm{H} \beta,[\mathrm{OIII}] \lambda 5007,[\mathrm{OI}] \lambda 6300, \mathrm{H} \alpha$, $[\mathrm{NII}] \lambda 6583,[\mathrm{SII}] \lambda 6716, \lambda 6731$. The strengths of the detectable emission lines after appropriate dereddening, as well as their equivalent widths, are presented in Table III. This object is a Starburst with narrow emission lines and $\lambda 6583 / H \alpha=0.22$. The ratio of the sulfur lines in the doublet can be used as a density diagnostic. We find that $[\mathrm{SII}](\lambda 6716 / \lambda 6731)=$ $1.0-1.4$, typical densities $100-500 \mathrm{~cm}^{-3}$.

The nuclear spectrum and other ones for different regions are presented in Figure 3 on the same scale to allow direct comparison. Figure 4 gives the heliocentric velocities and an asymmetric feature can be observed in the rotation curve.

ures 2(b) and 2(e) respectively, show that this 


\begin{tabular}{|c|c||c||c||c||c|c|}
\hline OPD/LNA & $\begin{array}{c}\text { Exp. Time } \\
(\mathrm{s})\end{array}$ & $\begin{array}{c}\text { PA } \\
(0)\end{array}$ & $\begin{array}{c}\text { Seeing } \\
(\operatorname{arcsec})\end{array}$ & Airmass & S/N & $\begin{array}{c}\text { Window } \\
\text { center }\end{array}$ \\
\hline 2006, June 28 & 1200 & 68 & 1.5 & 1.358 & 16 & Nucleus \\
\hline
\end{tabular}

TABELA I: Observational caracteristics (OPD/LNA).

\begin{tabular}{|c||c|c||c||c||c||c|}
\hline $\begin{array}{c}\text { Galaxy } \\
\text { (near names) }\end{array}$ & $\begin{array}{c}\mathrm{a} \\
(\mathrm{h} \mathrm{m} \mathrm{s})\end{array}$ & $\begin{array}{c}\mathrm{d} \\
\left(0^{\prime}{ }^{\prime}\right)\end{array}$ & $\begin{array}{c}\mathrm{v} \\
(\mathrm{km} \mathrm{s}-1)\end{array}$ & $\begin{array}{c}\mathrm{D}, \mathrm{d} \\
(\operatorname{arcmin})\end{array}$ & Mag (Filter) & Type \\
\hline HRG 02401 & 174916.25 & -790203 & $5384 \pm 29$ & $1.0,0.5$ & $14.8(\mathrm{~b})$ & SB \\
\hline
\end{tabular}

TABELA II: Basic parameters (NASA/IPAC Extragalactic Database).

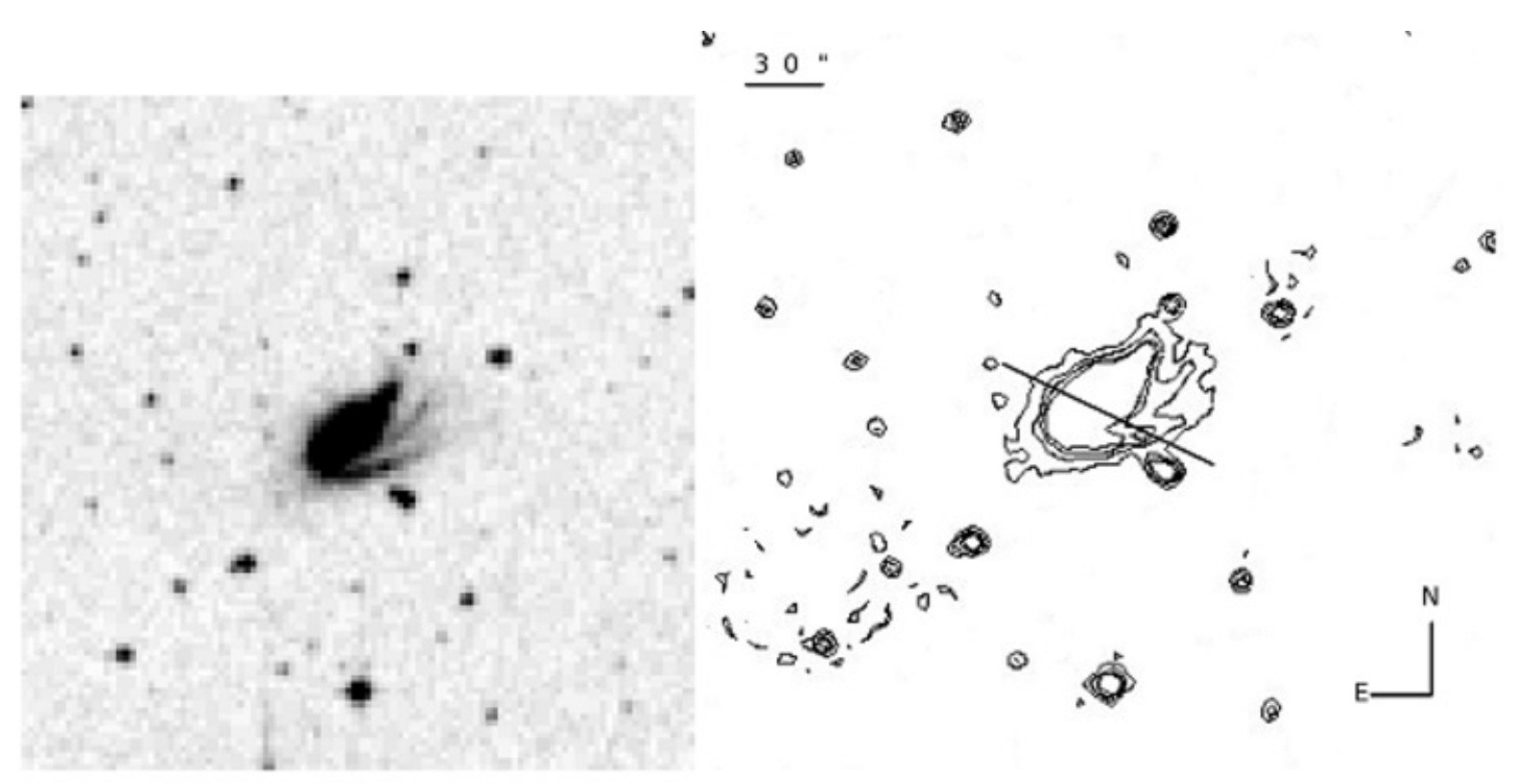

FIGURA 1: Contour plot of HRG 02401 galaxy in the optical from DSS, showing the orientation of the 3 arcsec wide longslit. Near names: AM 1740 - 790, ESO 024-IG 009.

is not the complete picture. In both diagrams the optical brightness has been over plotted with a dashed line for comparison. Both peaks are near close but not in the same position. This feature can suggest that the nucleus host a cluster of hot young OB stars which are producing a large ionizing flux. In such a situation we might expect $\mathrm{EWH} \alpha$ to change more slowly, which is the case, as further from the nucleus the continuum becomes more dominated by older redder stars. However, to the northeast (positive offset) the $\mathrm{H} \alpha$ flux decreases in soft way, while the optical brightness decreases abruptly. In the case of $\mathrm{EWH} \alpha$, we can see a small cutoff $( \pm 10$ arcsec $)$ suggest that the stellar population changes from hot $\mathrm{OB}$ stars to cooler non-ionizing ones, but this cannot be correct because the continuum color shows that the stars are still blue.

To understand it further, we need to know how the extinction varies across the nucleus. Since this can be calculated from the Balmer decrement, we have shown the ratio $\mathrm{H} \alpha / \mathrm{H} \beta$ in Figure 2(c), although it could be measured for 
some apertures in which $\mathrm{H} \alpha$ was strong enough to detect. The $\mathrm{H} \alpha$ flux has been over plotted (dotted line) to show that it is strongest were the extinction is lowest $(A V \gg 3 \mathrm{mag})$, and that the cut-off occurs where the extinction increases $3-5$ mag.

\section{Acknowledgments}

The authors are very grateful to the staff of Observatório do Pico dos Dias (LNA/MCT), for their assistance during the observations and to the Gemini Observatory.
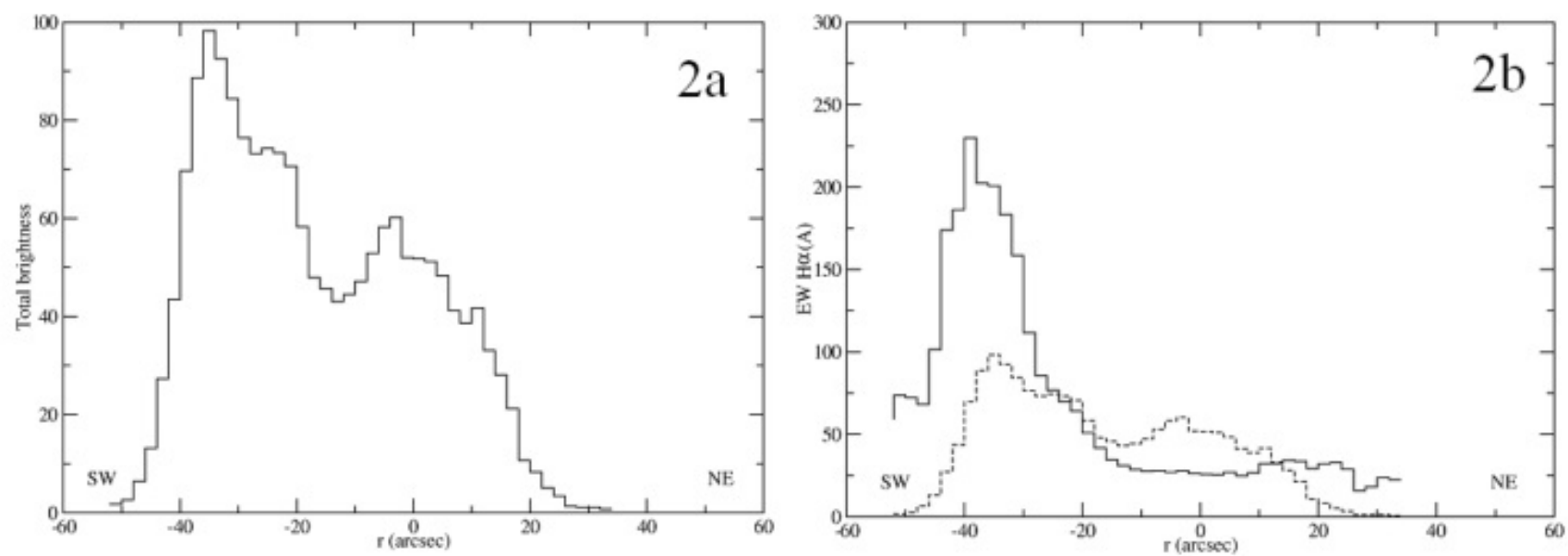

FIGURA 2: Mapped region of the longslit showing the variation along the slit. The individual frames (described in the text in more detail) are (a) total optical brightness, (b) observed $\mathrm{H} \alpha$ flux, (c) ratio $\mathrm{H} \alpha / \mathrm{H} \beta$, (d) continuum color, and (e) $\mathrm{H}$ equivalent width. Figure 2(a) shows the total brightness, computed as simply the total flux detected in each aperture, and figure $2(\mathrm{~d})$ shows the continuum color, i.e., the ratio of the continuum flux density at $\mathrm{H} \alpha$ to that at $\mathrm{H} \beta$, with the dotted line representing a flat continuum. The figure 2 (a) shows clearly that along the slit there is a bimodality observed in the region within \pm 20 arcsec (about $7 \mathrm{kpc}$ across, central and southwest peak), brighter and bluer, indicative of a starburst nucleus.
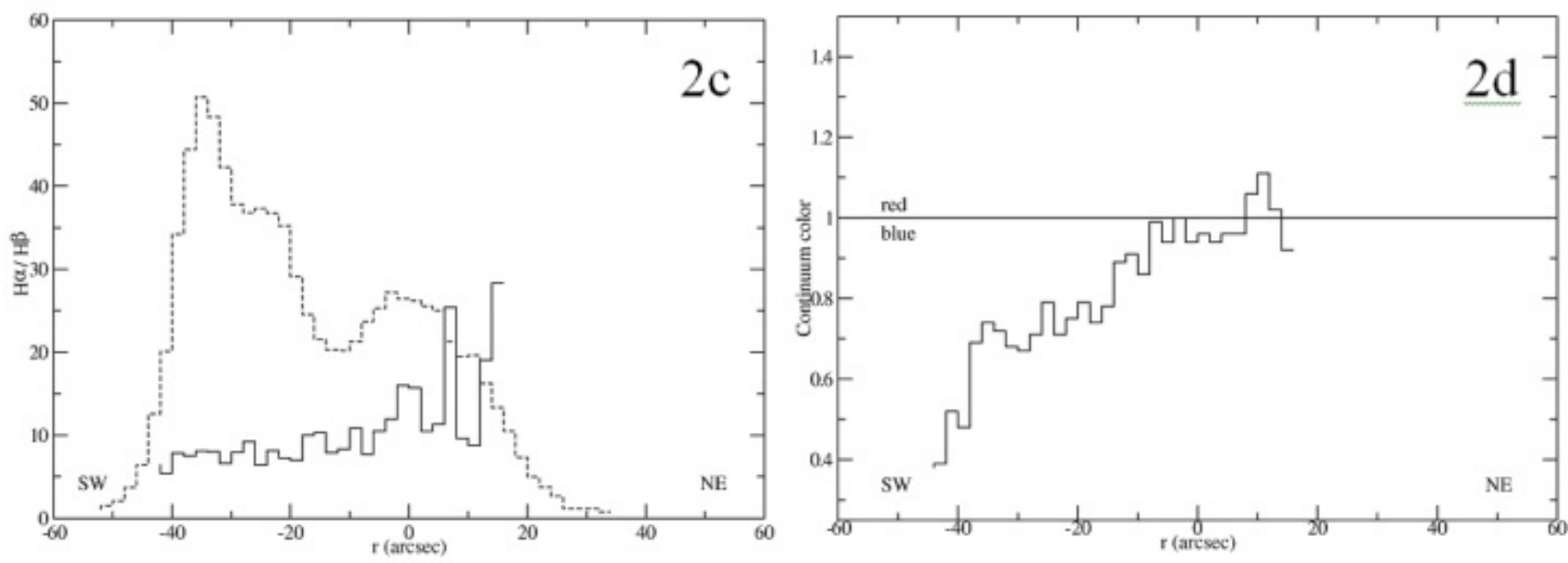


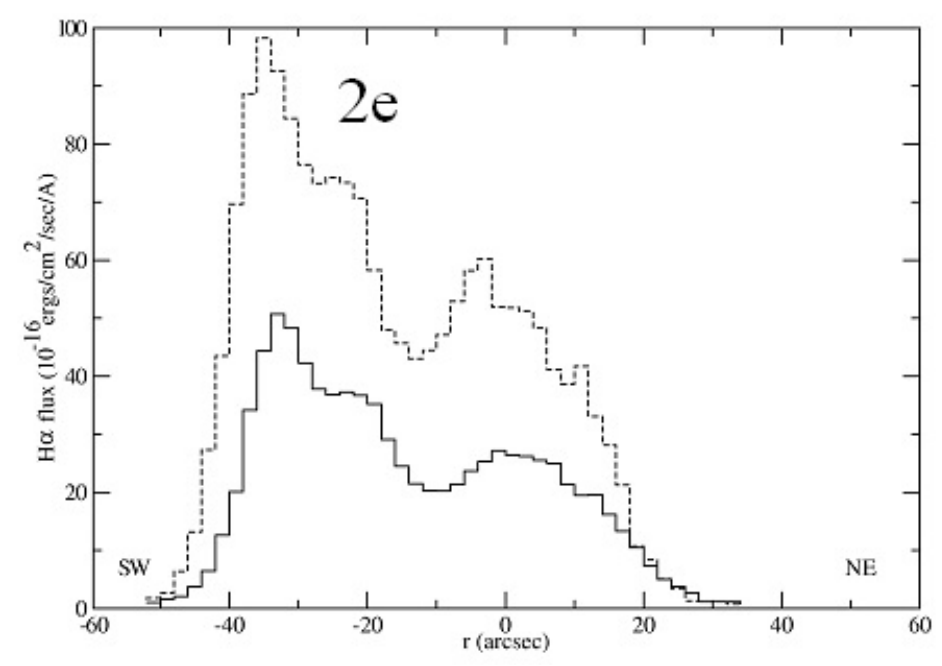

\begin{tabular}{|c||c|c|c||c|}
\hline Ion & Ap.1 (EW $\AA)$ & Ap. 5 (EW $\AA)$ & Ap. 35 (EW $\AA)$ & Ap. 37 (EW $\AA)$ \\
\hline \hline H $\lambda \lambda 4861$ & - & - & $98.3 \pm 7.52(16.99)$ & $166.0 \pm 11.09(17.72)$ \\
\hline \hline$[\mathrm{O}$ III] $\lambda 4959$ & - & - & $33.6 \pm 2.15(5.89)$ & $91.7 \pm 7.80(11.29)$ \\
\hline \hline$[\mathrm{O}$ III] $\lambda .5007$ & - & - & $122.0 \pm 10.01(21.66)$ & $294.0 \pm 21.56(36.32)$ \\
\hline \hline$[\mathrm{O} \mathrm{I}] \lambda 6300$ & - & $1.05 \pm 0.66(1.37)$ & $4.67 \pm 1.65(1.63)$ & $6.08 \pm 2.09(1.75)$ \\
\hline \hline$[\mathrm{N} \mathrm{II}] \lambda 6548$ & $2.89 \pm 0.97(2.07)$ & $1.76 \pm 0.74(2.40)$ & $16.2 \pm 3.33(8.70)$ & $19.7 \pm 3.00(7.82)$ \\
\hline \hline $\mathrm{H} \alpha \lambda 6563$ & $26.4 \pm 4.07(26.17)$ & $21.3 \pm 3.82(24.9)$ & $286.0 \pm 18.05(153.7)$ & $499.0 \pm 27.85(200.1)$ \\
\hline \hline$[\mathrm{N} \mathrm{II}] \lambda 6583$ & $8.72 \pm 2.48(8.70)$ & $5.32 \pm 1.98(6.24)$ & $46.0 \pm 3.63(24.85)$ & $69.1 \pm 5.65(28.03)$ \\
\hline \hline$[\mathrm{S} \mathrm{II}] \lambda 6716$ & $4.98 \pm 2.65(4.96)$ & $4.51 \pm 2.71(5.36)$ & $51.5 \pm 5.18(31.41)$ & $75.5 \pm 5.92(35.89)$ \\
\hline \hline$[\mathrm{S} \mathrm{II}] \lambda 6731$ & $4.07 \pm 2.98$ & $3.08 \pm 2.27(3.66)$ & $37.5 \pm 4.87(24.51)$ & $62.1 \pm 5.18(30.05)$ \\
\hline
\end{tabular}

TABELA III: Emission-lines intensities. Reddening-corrected fluxes in units of $10^{-16} \mathrm{erg} \mathrm{cm}^{-2} \mathrm{~s}^{-1} \AA^{-1}$.
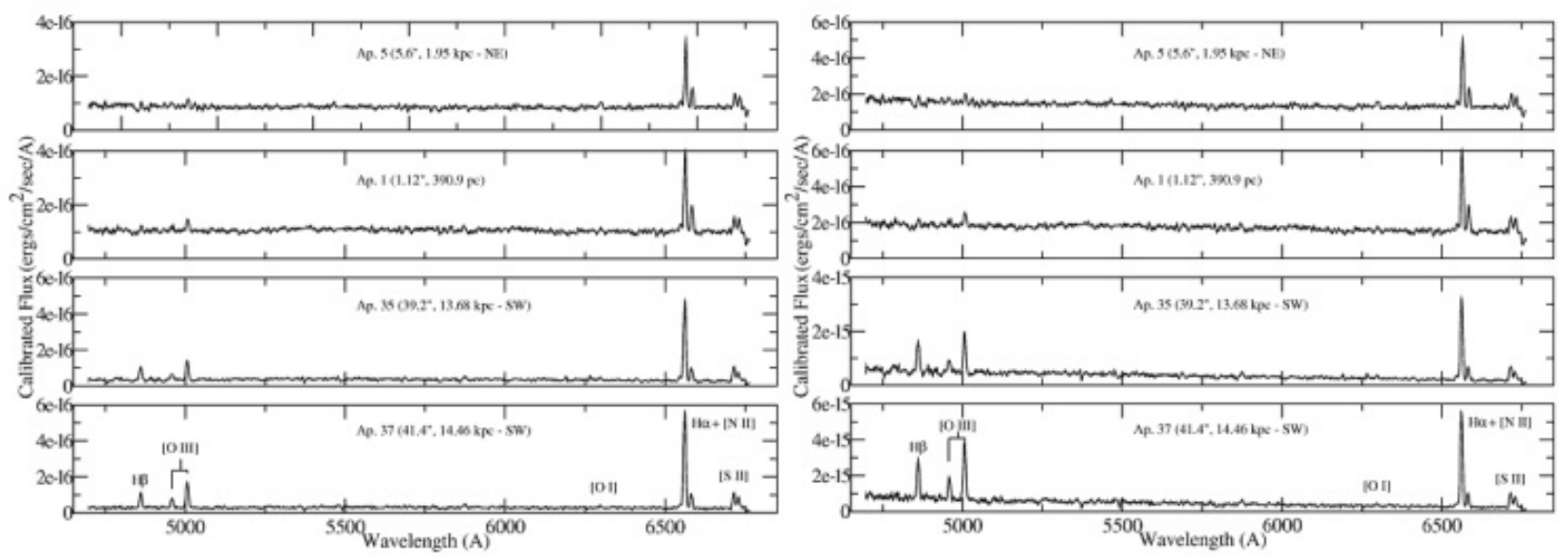

FIGURA 3: Spectra of the Starburst: left (not corrected) and right (corrected for extinction - only Galactic reddening for the apertures 1 and 5). 


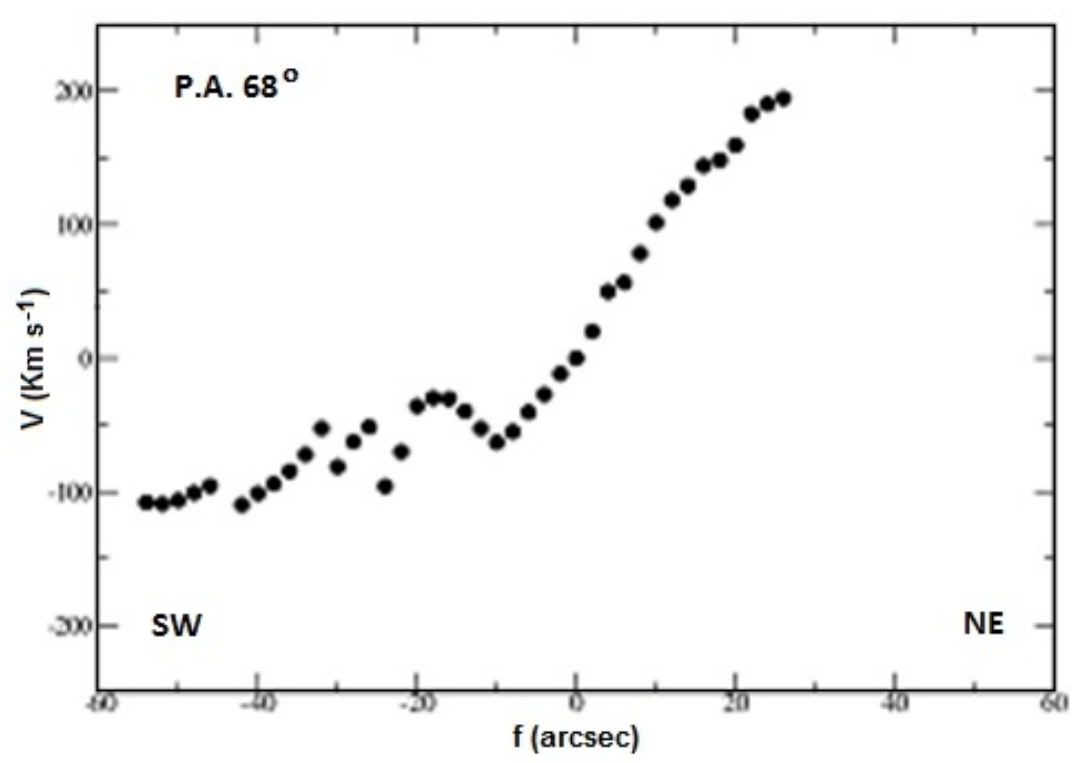

FIGURA 4: Heliocentric velocities. $1.12 \operatorname{arcsec}=390.9$ pc.

\begin{tabular}{|c|c|c|c|c|c|}
\hline & $\mathrm{H} \alpha / \mathrm{H} \beta$ & {$[\mathrm{O} \mathrm{III}] / \mathrm{H} \beta$} & {$[\mathrm{N} \mathrm{II}] / \mathrm{H \alpha}$} & {$[\mathrm{O} \mathrm{I}] / \mathrm{H \alpha}$} & {$[\mathrm{S} \mathrm{II}] / \mathrm{H \alpha}$} \\
\hline Aperture 1 & - & - & 0.82 & - & 0.34 \\
\hline Aperture 5 & - & - & 0.10 & 0.05 & 0.36 \\
\hline Aperture 35 & $2.91(7.04)$ & 1.24 & 0.16 & 0.02 & 0.31 \\
\hline Aperture 37 & $2.94(8.39)$ & 1.77 & 0.14 & 0.01 & 0.28 \\
\hline
\end{tabular}

TABELA IV: Emission-lines ratios.

[1] D.W. Weedman et at.. ApJ 248, 105 (1981).

[2] A. Constantin, M. Vogeley. ApJ 650, 727 (2006).

[3] M. Faúndez-Abans, M. de Oliveira-Abans. A \& AS 129, 357 (1998).

[4] L.C. Ho, A. Filippenko, W.L.W. Sargent. ApJS 112, 315 (1997).

[5] L.C. Ho, A. Filippenko, W.L.W. Sargent. ApJ 487, 568 (1997).

[6] L.J. Kewley, M.A. Dopita, R.S. Sutherland, C.A. Heisler, J. Trevena. ApJ 556, 121 (2001).

[7] L.J. Kewley, B. Groves, G. Kauffmann, T. Heckman. MNRAS 372, 961 (2006).

[8] S. Lípari et al.. MNRAS 355, 641 (2004).
[9] D.J. Mink, W.F. Wyatt. Astron. Soc. Pac. 77, 496 (1995). In: R.A. Shaw, H.E. Payne, J.J.E. Hayes (Eds.), Astronomical Data Analysis Software and Systems IV. San Francisco: ASP Conference Series (1995).

[10] D.E. Osterbrock, G.J. Ferland, Astrophysics of Gaseous Nebulae and Active Galactic Nuclei (2nd Edition). Mill Valley: University Science Books (2006).

[11] K. Rines, A.Diaferio, P. Natarajan. ApJ 657, 183 (2007).

[12] S. Veilleux, D.E. Osterbrock. ApJS 63, 295 (1987). 